\title{
Boehmite Nanofiber-Reinforced Resorcinol-Formaldehyde Macroporous Monoliths for Heat/Flame Protection
}

Gen Hayase*

Frontier Research Institute for Interdisciplinary Sciences, Tohoku University, 6-3 Aramaki-aza Aoba, Aoba-ku, Sendai 980-8578, Japan.

*Email: gen@aerogel.jp

Keywords. sol-gel, macroporous monoliths, nanofibers, resorcinol-formaldehyde, thermal insulation

\begin{abstract}
By distributing boehmite nanofibers (BNFs) to a resorcinol-formaldehyde (RF) skeletal phase formed by phase separation in an aqueous sol, composite macroporous monoliths have been produced. The nanofiber reinforced monoliths have a skeleton in which BNF is arranged in parallel within the RF structure, and showed high Young's modulus against uniaxial compression for their bulk density. These materials can be expected to be applied to heat/flame protection materials using heat insulating properties and high flame resistance.
\end{abstract}

\section{Main Text}

Macroporous monoliths composed of ceramics, organic polymers, and natural products have long been used for various applications. ${ }^{1}$ The macroscopic physical properties of these materials have led to their use for heat insulation, sound absorption, and cushioning. The utility of macroporous 
monoliths as catalysts, battery materials, separation media, and small sensors are currently being investigated. ${ }^{2}$ Unlike powders or thin films, porous monoliths have a three-dimensional macroscopic structure. The controlled alteration of the structure and surface of porous monoliths allows the controlled alteration of physical properties and is an important area of research in both academia and industry. Increasing interest in energy conservation, the miniaturization of computer equipment, and the growth of private space industries are driving the need for high-performance heat insulating and shielding materials. This has led to increased research on porous materials due to their thermal insulation properties. In general, porous monoliths have a lower bulk density and finer structure than other materials, giving rise to attractive characteristic physical properties but also decreased mechanical strength. ${ }^{2-3}$

Various studies have focused on increasing the mechanical strength of low-bulk-density porous monoliths. For example, the composition and morphology of the microstructure can be optimized by polymer modification of the skeleton and fiber reinforcement of the exterior of the material. ${ }^{4-7}$ We are investigating the use of organic-inorganic hybrid composites of flexible porous monoliths. Methylsilsesquioxane transparent aerogels $\left(\mathrm{CH}_{3} \mathrm{SiO}_{1.5}\right)$ do not collapse when deformed $50-80 \%$ by uniaxial compression and show superinsulating properties. ${ }^{8-10}$ The thermal conductivity of these materials is below $15 \mathrm{~mW} \mathrm{~m}^{-1} \mathrm{~K}^{-1}$, but they are fragile when subjected to bending and twisting, preventing their practical use. Flexible macroporous silicone materials "marshmallow-like gels" have a thermal conductivity of $30 \mathrm{~mW} \mathrm{~m}^{-1} \mathrm{~K}^{-1}$ but their flexibility and environment resistance makes their use practical. ${ }^{11-12}$ Such materials can be used as "simple dry shippers" for storing frozen embryos and tissues at $-150{ }^{\circ} \mathrm{C}$ or lower by having them absorb liquid nitrogen, ${ }^{13}$ but they are fragile when subjected to tension and friction. Improving the mechanical properties of porous monoliths for a wide application requires the design of composite materials whose microstructures are resistant to collapse. Fiber reinforced plastic (FRP) is used as a 
structural material for aircraft and vehicles and as a building material and exhibits excellent mechanical properties due to the impregnation and integration of resin with glass, carbon, or ceramic fibers. The excellent mechanical properties of FRP cannot be obtained by using plastics alone. Conventional fiber-composite porous monoliths with improved strength contain fibers outside the main skeleton or are covered with spherical particle aggregates. ${ }^{14-17}$ Preparing such monoliths with increased strength without coarsening the microstructure and sacrificing other physical properties is challenging. Furthermore, the microstructure is reinforced by using nanofibers, but these fine fibers tend to form a bundle structure and are thus difficult to handle.

We have produced porous monoliths by using boehmite nanofibers (BNFs) containing aluminum oxide hydroxide $(\mathrm{AlOOH}) .{ }^{18-20}$ Those nanofibers have a high aspect ratio ( $4 \mathrm{~nm}$ average diameter, $1.2 \mu \mathrm{m}$ average length) and show high dispersibility, which stabilizes over several months in acetic acid aqueous solution. ${ }^{21}$ However, these nanofibers can quickly aggregate and gel upon changing the $\mathrm{pH}$ or adding a phosphoric acid compound.${ }^{18}$ In 2016, we reported a simple method for the generation of low-bulk-density porous monoliths by adding a tri-functional silicon alkoxide to a BNF dispersion under acidic conditions. ${ }^{22}$ The alkoxide undergoes hydrolysis/polycondensation under acidic conditions to form silsesquioxane that covers each BNF and at the same time bonds the fibers together. Consequently, monoliths consisting of a rod-like skeleton with a diameter of several tens of nanometers can be obtained with good reproducibility. The mechanism of formation indicates that the skeleton has a core-shell-type structure in which BNF is surrounded by silsesquioxane, providing a material with excellent mechanical strength. This low-bulk-density BNF-PMSQ porous monolith acts as a high thermal insulator in low vacuum, and its application as an insulating material in vacuum environments is currently being investigated. However, the mechanism by which such core-shell structures are formed remains unclear, and BNF-silsesquioxane remains the only BNF-PMSQ reported to date. In this paper, I 
describe our attempts to fabricate nanofiber-reinforced macroporous monoliths by using distributability during phase separation, with the aim of establishing a general method applicable to other composites.

Since BNFs are stably dispersed in weak aqueous acid, the skeletal phase of the macroporous monolith can likely be formed through a polycondensation reaction by acid catalysis. I prepared a composite material with BNFs using a resorcinol-formaldehyde composite as the skeletal phase in aqueous acetic acid. ${ }^{23}$ The sample preparation procedure is as follows. (1) The BNF dispersion was diluted to $x$ wt $\%$ with water and acetic acid to have an acetic acid concentration of 1 M. (2) Resorcinol (2.2 $\times y \mathrm{~g})$ was dissolved in $8 \mathrm{~mL}$ of diluted BNF dispersion, then $3.0 \times y \mathrm{~mL}$ of $37 \%$ formaldehyde aqueous solution was added. The mixture was stirred at room temperature for $10 \mathrm{~min}$. (3) The resultant sol was poured into a sealed mold, then allowed to stand in a $60{ }^{\circ} \mathrm{C}$ oven for $12 \mathrm{~h}$ for gelation and aging. (4) The obtained gel was immersed in water and ethanol to remove unreacted reagents, then dried at $60{ }^{\circ} \mathrm{C}$. The physical properties of the prepared samples, RB- $x-y$, are shown in Table 1. All the samples had macroporous structures, and the skeleton became finer due to the addition of BNF (Figure 1, Figure S1). The TEM images of the samples RB-x-2 in Figure 2 show BNFs in the skeleton. No obvious bundle structures surround the BNFs, and each fiber was individually dispersed within the resorcinol-formaldehyde skeletal phase. In the composition RB-0.23-2 with a low BNF concentration, BNFs are arranged in random directions within the framework of the monolith, whereas many BNFs are aligned almost parallel to the skeleton about RB-3.6-2, RB-1.8-2, and RB-0.90-2. Because BNFs have a high aspect ratio with a length of micrometers, they likely align in parallel preferentially when the diameter of the skeleton becomes smaller than the length of the nanofibers. The bulk density and the porosity of the representative sample RB-3.6-2 were $0.27 \mathrm{~g} \mathrm{~cm}^{-3}$ and $82 \%$, respectively. 
Table 1. Properties of the RF and the RF-BNF monoliths.

\begin{tabular}{|c|c|c|c|c|c|c|}
\hline Sample & $\begin{array}{l}\text { BNF } \\
\text { concentration } \\
\text { of a sol }[\%]\end{array}$ & $\begin{array}{l}\text { Resorcinol } \\
{[\mathrm{g}]}\end{array}$ & $\begin{array}{l}37 \% \\
\text { Formaldehyde } \\
{[\mathrm{mL}]}\end{array}$ & $\begin{array}{l}\text { Bulk } \\
\text { density } \\
{\left[\mathrm{g} \mathrm{cm}^{-3}\right]}\end{array}$ & $\begin{array}{l}\text { Young's } \\
\text { modulus } \\
{[\mathrm{MPa}]}\end{array}$ & $\begin{array}{l}\text { Thermal } \\
\text { conductivity } \\
{\left[\mathrm{mW} \mathrm{m}^{-1} \mathrm{~K}^{-1}\right]}\end{array}$ \\
\hline RB-0-4 & 0 & 8.8 & 12.0 & 0.501 & 23.1 & \\
\hline RB-3.6-4 & 3.6 & 8.8 & 12.0 & 0.396 & 23.9 & 47.3 \\
\hline RB-1.8-4 & 1.8 & 8.8 & 12.0 & 0.406 & 24.3 & \\
\hline RB-0.90-4 & 0.90 & 8.8 & 12.0 & 0.404 & 25.4 & \\
\hline RB-0-2 & 0 & 4.4 & 6.0 & 0.284 & 1.07 & \\
\hline RB-3.6-2 & 3.6 & 4.4 & 6.0 & 0.272 & 9.17 & 39.0 \\
\hline RB-1.8-2 & 1.8 & 4.4 & 6.0 & 0.274 & 10.2 & \\
\hline RB-0.90-2 & 0.90 & 4.4 & 6.0 & 0.269 & 11.6 & \\
\hline RB-0.23-2 & 0.23 & 4.4 & 6.0 & 0.418 & 10.4 & \\
\hline RB-0-1 & 0 & 2.2 & 3.0 & 0.203 & 0.26 & \\
\hline RB-1.8-1 & 1.8 & 2.2 & 3.0 & 0.244 & 4.09 & \\
\hline RB-0.90-1 & 0.90 & 2.2 & 3.0 & 0.217 & 1.92 & \\
\hline
\end{tabular}

In RB-3.6-1 composition, the obtained gel became heterogeneous. 


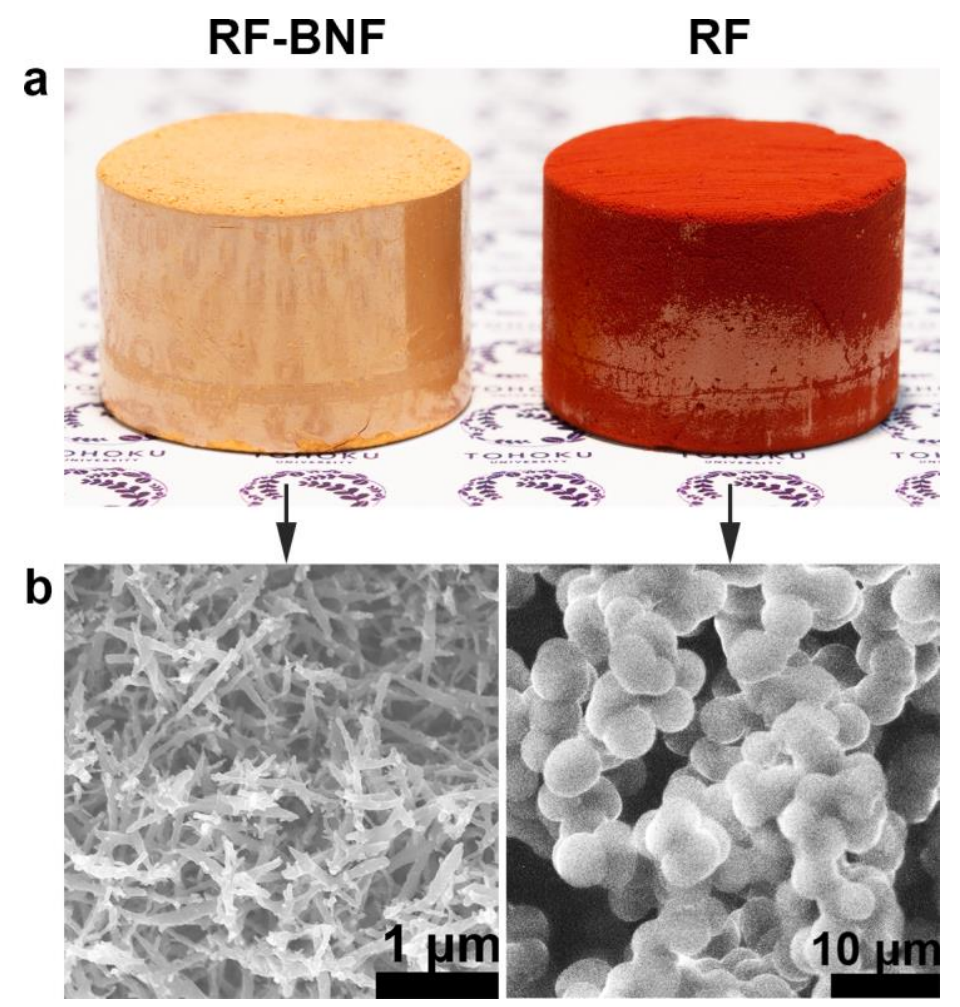

Figure 1. (a) Photograph, and (b) SEM images of the RF-BNF and RF monoliths (RB-3.6-2 and RB-0-2, respectively). The diameter of the monoliths is about $26 \mathrm{~mm}$. See also Figure S1. 

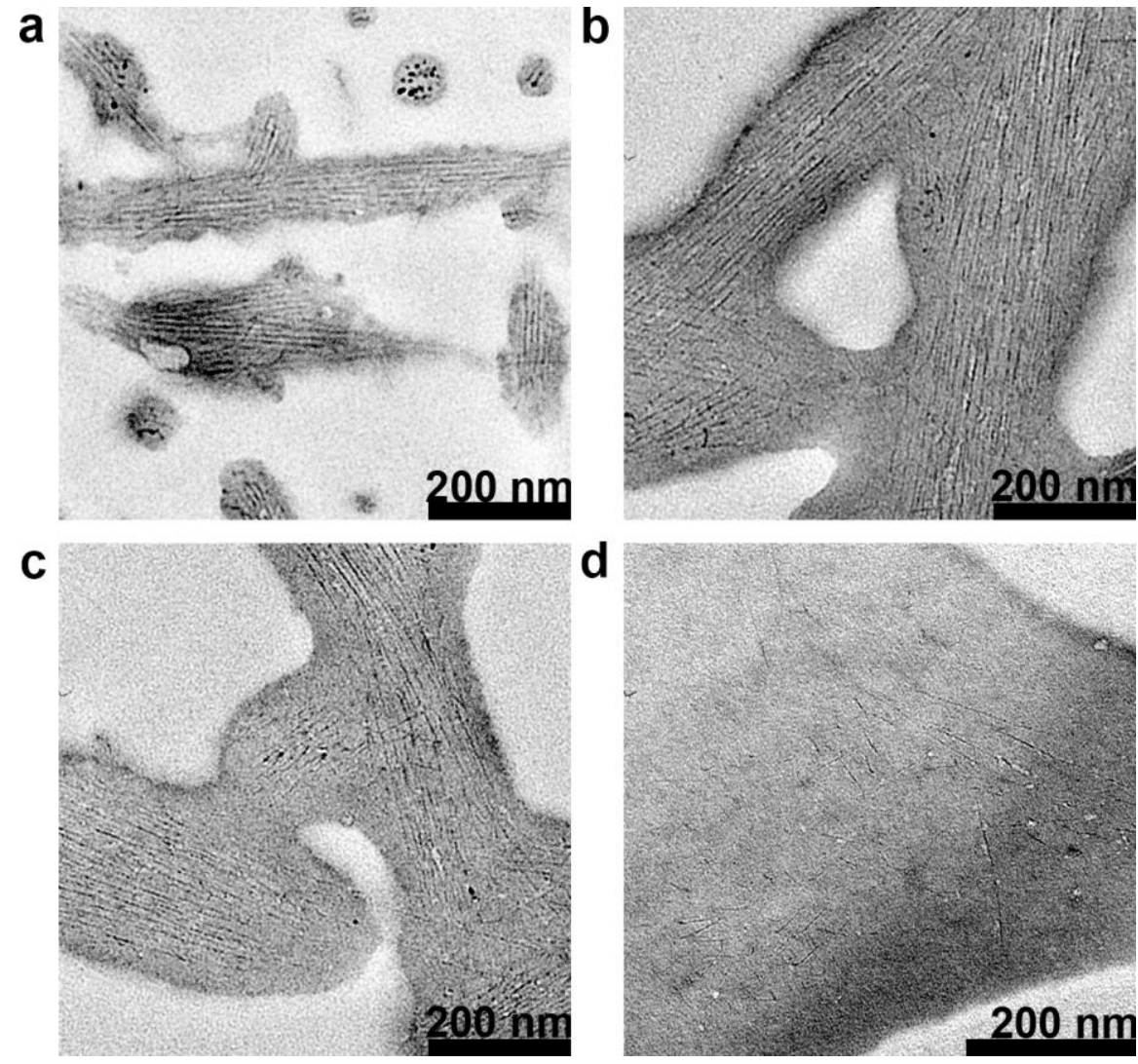

Figure 2. TEM images of RF-BNF monoliths (a) RB-3.6-2, (b) RB-1.8-2, (c) RB-0.90-2 and (d) RB-0.23-2, fabricated by changing the amount of BNF added. Boehmite nanofibers are aligned almost parallel to the skeleton about the samples RB-3.6-2, RB-1.8-2 and RB-0.90-2, while arranged in random in the composition RB-0.23-2.

Generally, the structure of an anisotropic composite has higher strength than composites with a random structure. Figure 3 shows the relationship between the bulk density and the Young's modulus against uniaxial compression of RF and RF-BNF monoliths. The addition of BNFs into the skeleton increased the Young's modulus for a given bulk density, and all the samples recovered fully following a compression deformation of $5-10 \%$. As estimated from various other FRP materials, these mechanical properties are expected to be the result of the nanofiber reinforcement like plant stem structure, though some effect of morphological change cannot be excluded. ${ }^{24-25}$ 
Future research including computer simulations may allow finer control of the mechanical properties of monoliths.



Figure 3. The relationship between bulk density and Young's modulus against uniaxial compression in RF and RF-BNF monoliths. Except for the sample RB-0.23-2 in which BNF is oriented randomly, Young's modulus increased with respect to bulk density by adding BNF.

The morphologies of RF porous materials have previously been controlled by altering the fabrication conditions. ${ }^{26-28}$ It has been reported that the thermal conductivity of low-bulkdensity RF monoliths decreases upon appropriate control of the pore size, leading to research and development on RF monoliths as heat insulating materials. ${ }^{29-31}$ The thermal conductivity of the RF-BNF monolithic panel with RB-3.6-2 composition was $39 \mathrm{~mW} \mathrm{~m}{ }^{-1} \mathrm{~K}^{-1}$ measured by heat flow method at room temperature, equivalent to high-performance glass wool insulation material. Both phenolic resin and RF resin are flame resistant due to their molecular structure and thus can be used as heat-resistant/heat-shielding materials for space hardware applications. ${ }^{32}$ If the thermal 
capacity of RF resin is the same as that of phenolic resin $1.6 \mathrm{~kJ} \mathrm{~kg}^{-1} \mathrm{~K}^{-1}$, then the thermal diffusivity of RB-3.6-2 was $0.9 \mathrm{~m}^{2} \mathrm{~s}^{-1}$. This value is close to that of heat resistant cork-phenol resin composites and carbon composites used for rocket components. ${ }^{33-34} \mathrm{I}$ anticipate further improving our materials by optimizing the molecular structure of the resin in the skeletal phase. I also investigated flame resistance by applying a liquefied natural gas flame $\left(\sim 1700^{\circ} \mathrm{C}\right)$ to the RF-BNF monolith (Figure 4, Movie S1). Although carbonization occurred gradually and the outermost surface cracked due to shrinkage, the monolith did not collapse, and the shape did not change greatly even if a flame was applied for 10 min or longer. The boehmite contained in the skeleton undergoes a dehydration reaction at high temperature and is transformed into alumina, and thus its combination with formaldehyde-phenolic resin should provide material useful for flame-resistant applications. RF-BNF porous monoliths and their derivatives hold promise as materials for space development, such as in ablators used for thermal protection during atmospheric re-entry. In the future, I will modify our equipment and conduct tests at higher temperatures.
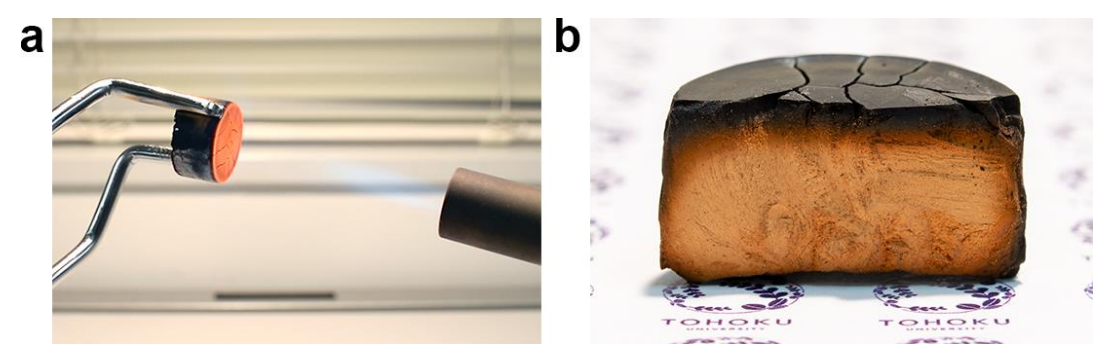

Figure 4. (a) Photographs of a flame resistance test on the RF-BNF monolith RB-3.6-2. The diameter of the monoliths is about $26 \mathrm{~mm}$. (b) Cross-section photo of the resultant sample after 40 seconds exposure to flame. Only the surface was carbonized, and noticeable collapse had not occurred. See also Movie S1. 
In summary, I have produced composite macroporous monoliths by distributing nanofibers to the skeletal phase in RF porous structures formed by phase separation in an aqueous sol. The diameter of the composite skeleton decreased as the BNF concentration increased and the nanofibers were oriented parallel to the skeleton. The addition of a small amount of BNF increased the Young's modulus for compression. The thermal conductivity of a composite monolithic panel was $39 \mathrm{~mW} \mathrm{~m}^{-1} \mathrm{k}^{-1}$, indicative of high flame resistance. There have been few reports of methods for the preparation of porous monoliths reinforced with nanofibers inside the fine skeleton. Our simple method for the generation of porous nanofiber-reinforced material is likely applicable to other resins, leading to various high-strength monoliths in the future.

\section{Acknowledegment}

This research was supported by Japan Society for the Promotion of Science (JSPS) Grants-in-Aid for Scientific Research (KAKENHI, No. 17K14541). 


\section{References}

1. Gibson, L. J.; Ashby, M. F., Cellular Solids: Structure and Properties. 2nd Edition ed.; Cambridge University Press: Cambridge, UK, 1999.

2. Gesser, H. D.; Goswami, P. C., Aerogels and Related Porous Materials. Chemical Reviews 1989, 89 (4), 765-788.

3. Brinker, C. J.; Scherer, G. W., Sol-Gel Science: The Physics and Chemistry of Sol-Gel Processing. Academic Press: San Diego, 1990.

4. Zhang, G.; Dass, A.; Rawashdeh, A.-M. M.; Thomas, J.; Counsil, J. A.; SotiriouLeventis, C.; Fabrizio, E. F.; Ilhan, F.; Vassilaras, P.; Scheiman, D. A.; McCorkle, L.; Palczer, A.; Johnston, J. C.; Meador, M. A.; Leventis, N., Isocyanate-crosslinked silica aerogel monoliths: preparation and characterization. J. Non-Cryst. Solids 2004, 350, 152-164.

5. Meador, M. A. B.; Fabrizio, E. F.; Ilhan, F.; Dass, A.; Zhang, G.; Vassilaras, P.; Johnston, J. C.; Leventis, N., Cross-linking Amine-Modified Silica Aerogels with Epoxies: Mechanically Strong Lightweight Porous Materials. Chem. Mater. 2005, 17 (5), 1085-1098.

6. Guo, H.; Nguyen, B. N.; McCorkle, L. S.; Shonkwiler, B.; Meador, M. A. B., Elastic low density aerogels derived from bis 3-(triethoxysilyl)propyl disulfide, tetramethylorthosilicate and vinyltrimethoxysilane via a two-step process. J. Mater. Chem. 2009, 19 (47), 9054-9062.

7. Meador, M. A. B.; Aleman, C. R.; Hanson, K.; Ramirez, N.; Vivod, S. L.; Wilmoth, N.; McCorkle, L., Polyimide Aerogels with Amide Cross-Links: A Low Cost Alternative for Mechanically Strong Polymer Aerogels. ACS Appl. Mater. Interfaces 2015, 7 (2), 1240-1249.

8. Kanamori, K.; Aizawa, M.; Nakanishi, K.; Hanada, T., New Transparent Methylsilsesquioxane Aerogels and Xerogels with Improved Mechanical Properties. Adv. Mater. 2007, 19 (12), 1589-1593.

9. Hayase, G.; Kugimiya, K.; Ogawa, M.; Kodera, Y.; Kanamori, K.; Nakanishi, K., The thermal conductivity of polymethylsilsesquioxane aerogels and xerogels with varied pore sizes for practical application as thermal superinsulators. J. Mater. Chem. A 2014, 2 (18), 6525-6531.

10. Hayase, G.; Kanamori, K.; Maeno, A.; Kaji, H.; Nakanishi, K., Dynamic spring-back behavior in evaporative drying of polymethylsilsesquioxane monolithic gels for low-density transparent thermal superinsulators. J. Non-Cryst. Solids 2016, 434, 115-119.

11. Hayase, G.; Kanamori, K.; Nakanishi, K., New flexible aerogels and xerogels derived from methyltrimethoxysilane/dimethyldimethoxysilane co-precursors. J. Mater. Chem. 2011, 21 (43), 17077-17079.

12. Hayase, G.; Kanamori, K.; Fukuchi, M.; Kaji, H.; Nakanishi, K., Facile Synthesis of Marshmallow-like Macroporous Gels Usable under Harsh Conditions for the Separation of Oil and Water. Angew. Chem., Int. Ed. 2013, 52 (7), 1986-1989.

13. Hayase, G.; Ohya, Y., Marshmallow-like silicone gels as flexible thermal insulators and 
liquid nitrogen retention materials and their application in containers for cryopreserved embryos. Appl. Mater. Today 2017, 9, 560-565.

14. Parmenter, K. E.; Milstein, F., Mechanical properties of silica aerogels. J. Non-Cryst. Solids 1998, 223 (3), 179-189.

15. Li, L. C.; Yalcin, B.; Nguyen, B. N.; Meador, M. A. B.; Cakmak, M., Flexible NanofiberReinforced Aerogel (Xerogel) Synthesis, Manufacture, and Characterization. ACS Appl. Mater. Interfaces 2009, 1 (11), 2491-2501.

16. Feng, J. Z.; Zhang, C. R.; Feng, J.; Jiang, Y. G.; Zhao, N., Carbon Aerogel Composites Prepared by Ambient Drying and Using Oxidized Polyacrylonitrile Fibers as Reinforcements. ACS Appl. Mater. Interfaces 2011, 3 (12), 4796-4803.

17. Li, Z.; Gong, L. L.; Cheng, X. D.; He, S.; Li, C. C.; Zhang, H. P., Flexible silica aerogel composites strengthened with aramid fibers and their thermal behavior. Mater. Des. 2016, 99, 349-355.

18. Hayase, G.; Nonomura, K.; Hasegawa, G.; Kanamori, K.; Nakanishi, K., UltralowDensity, Transparent, Superamphiphobic Boehmite Nanofiber Aerogels and Their Alumina Derivatives. Chem. Mater. 2015, 27 (1), 3-5.

19. Hayase, G., Facile Fabrication of Ultralow-Density Transparent Boehmite Nanofiber Cryogel Beads and Their Application to a Nanoglue. ChemNanoMat 2017, 3 (3), 168-171.

20. Hayase, G.; Funatomi, T.; Kumagai, K., Ultralow-Bulk-Density Transparent Boehmite Nanofiber Cryogel Monoliths and Their Optical Properties for a Volumetric Three-Dimensional Display. ACS Appl. Nano Mater. 2018, 1 (1), 26-30.

21. Nagai, N.; Mizukami, F., Properties of boehmite and A12O3 thin films prepared from boehmite nanofibres. J. Mater. Chem. 2011, 21 (38), 14884-14889.

22. Hayase, G.; Nonomura, K.; Kanamori, K.; Maeno, A.; Kaji, H.; Nakanishi, K., Boehmite Nanofiber-Polymethylsilsesquioxane Core-Shell Porous Monoliths for a Thermal Insulator under Low Vacuum Conditions. Chem. Mater. 2016, 28 (10), 3237-3240.

23. Brandt, R.; Petricevic, R.; Probstle, H.; Fricke, J., Acetic acid catalyzed carbon aerogels. J. Porous. Mater. 2003, 10 (3), 171-178.

24. Pekala, R. W.; Alviso, C. T.; Lemay, J. D., Organic Aerogels: Microstructural Dependence of Mechanical Properties in Compression. J. Non-Cryst. Solids 1990, 125 (1-2), 6775.

25. Woignier, T.; Reynes, J.; Alaoui, A. H.; Beurroies, I.; Phalippou, J., Different kinds of structure in aerogels: relationships with the mechanical properties. J. Non-Cryst. Solids 1998, 241 (1), 45-52.

26. Pekala, R. W., Organic aerogels from the polycondensation of resorcinol with formaldehyde. J. Mater. Sci. 1989, 24 (9), 3221-3227. 
27. Pekala, R. W.; Alviso, C. T.; Kong, F. M.; Hulsey, S. S., Aerogels derived from multifunctional organic monomers. J. Non-Cryst. Solids 1992, 145 (1-3), 90-98.

28. Al-Muhtaseb, S. A.; Ritter, J. A., Preparation and properties of resorcinol-formaldehyde organic and carbon gels. Adv. Mater. 2003, 15 (2), 101-114.

29. Lu, X.; Wang, P.; Arduinischuster, M. C.; Kuhn, J.; Buttner, D.; Nilsson, O.; Heinemann, U.; Fricke, J., Thermal transport in organic and opacified silica monolithic aerogels. J. Non-Cryst. Solids 1992, 145 (1-3), 207-212.

30. Lu, X.; Arduinischuster, M. C.; Kuhn, J.; Nilsson, O.; Fricke, J.; Pekala, R. W., Thermal conductivity of monolithic organic aerogels. Science 1992, 255 (5047), 971-972.

31. Lu, X.; Nilsson, O.; Fricke, J.; Pekala, R. W., Thermal and electrical conductivity of monolithic carbon aerogels. J. Appl. Phys. 1993, 73 (2), 581-584.

32. Vankrevelen, D. W., Some Basic Aspects of Flame Resistance of Polymeric Materials. Polymer 1975, 16 (8), 615-620.

33. Sato, Y.; Ohtake, K.; Shimada, T.; Sato, E., Evaluation of Thermal Diffusivity of Rocket Nozzle Materials. Netsu Bussei 2003, 17 (3), 199-204.

34. Aerospace | Materials \& Applications > Amorim Cork Composites. https://amorimcorkcomposites.com/en-us/materials-applications/aerospace/. 
Graphical Abstract

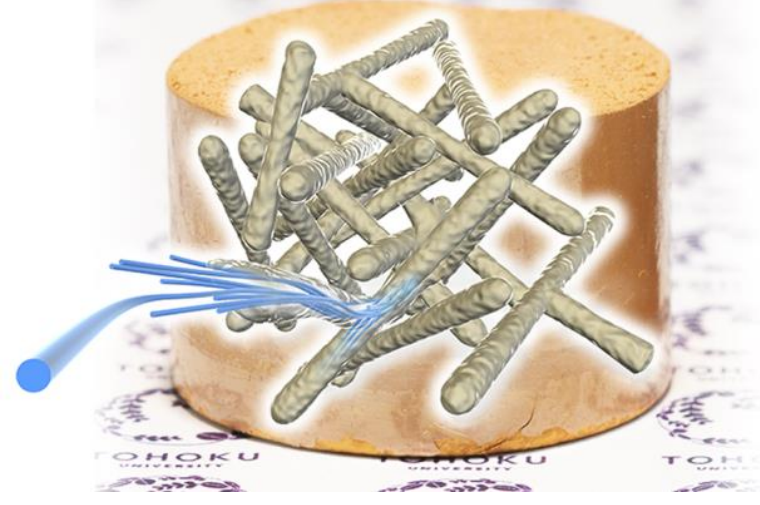

